\title{
A new experimental model for acute hepatic failure in rats $^{1}$
}

\author{
Novo modelo experimental em ratos para insuficiência hepática aguda
}

\author{
Antonio Roberto Franchi Teixeira', Marcel Cerqueira Cesar Machado"II, Márcia Saldanha Kubrusly"II, Nilza Trindade Molan ${ }^{\mathrm{III}}$, \\ Marta Bellodi-Privato ${ }^{\text {III, }}$ Kátia Regina Leite ${ }^{\mathrm{IV}}$, Luiz Augusto Carneiro D'Albuquerque ${ }^{\mathrm{V}}$
}

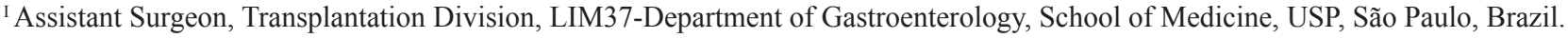

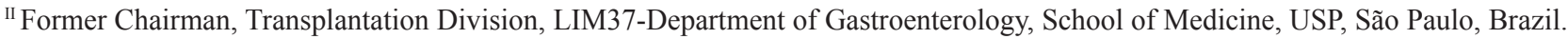

${ }^{\text {III }}$ Pharmacist, Transplantation Division, LIM37-Department of Gastroenterology, School of Medicine, USP, São Paulo, Brazil.

Iv Assistant Pathologist, Department of Urology, School of Medicine, USP, São Paulo, Brazil.

${ }^{\vee}$ Chairman and Professor, Transplantation Division, LIM37-Department of Gastroenterology, School of Medicine, USP, São Paulo, Brazil.

\begin{abstract}
Purpose: To develop a reliable surgical model of acute hepatic failure and hyperammonemia in rats that avoids porto-systemic shunt and bile duct ligation, applicable to hepatic encephalopathy research. Methods: The pedicles of right lateral and caudate lobes were exposed and clamped. One hour later, the animal was reopened, clamps were released and anterior subtotal hepatectomy (resection of median and left lateral lobes) was performed, comprising $75 \%$ of liver removal. Four hours after hepatectomy, blood samples and liver tissues were collected from ALF and control groups. Results: Differences between ALF and control groups were significant for ALT, AST, total and direct bilirubin, sodium, potassium, alkaline phosphatasis, gamma-glutamyltransferase and most important, ammonia. Histologically, significant differences were noticed between groups. Conclusion: The model is useful for the study of specific aspects of ALF and the development of new therapeutic approaches.
\end{abstract}

Key words: Liver Failure, Acute. Brain Diseases. Rats.

\section{RESUMO}

Objetivo: Desenvolver um modelo cirúrgico de IHA e hiperamonemia em ratos, que evita o shunt porto-sistêmico e a ligadura do ducto biliar, que seja aplicável à pesquisa de encefalopatia hepática. Métodos: Após anestesia geral e laparotomia mediana, os pedículos dos lobos laterais direito e caudado foram isolados e clampeados. Após 1 hora, o animal foi reaberto, os clampes retirados e foi realizada hepatectomia anterior subtotal (ressecção dos lobos médio e lateral esquerdo), compreendendo a remoção de 75\% do parênquima. Quatro horas após a hepatectomia, amostras de sangue e tecido hepático foram coletadas nos grupos IHA e controle. Resultados: Diferenças entre os grupos IHA e controle foram significativas para ALT, AST, bilirrubina total e direta, sódio, potássio, fosfatase alcalina, gama glutamiltransferase e principalmente amônia. Histologicamente, diferenças significativas foram observadas entre os grupos. Conclusão: O modelo é útil para o estudo de aspectos específicos da IHA e o desenvolvimento de novas abordagens terapêuticas.

Descritores: Falência Hepática Aguda. Encefalopatias. Rats.

${ }^{1}$ Research performed at Transplantation Division, Laboratory of Medical Investigation, Department of Gastroenterology, School of Medicine, University of São Paulo (USP), Brazil.

\section{Introduction}

Acute liver failure (ALF) is a morbid condition that may result in severe neurological complications such as hepatic encephalopathy and brain edema leading to intracranial hypertension, brain herniation, and death. Despite several advances in the clinical management of patients with acute liver failure (ALF), this condition remains extremely serious and results in high mortality rates. Viral hepatitis and drug-induced hepatotoxicity (in particular acetaminophen overdose) are the most frequent causes of ALF, although their relative incidence varies markedly in different parts of the world ${ }^{1}$. The difficulties inherent to the management of patients with ALF can be explained in part by the serious systemic and neurological complications of ALF, which include hypoglycemia, renal failure, coagulopathy, sepsis, multiorgan failure, intracranial hypertension, and hepatic encephalopathy ${ }^{2}$. Liver transplantation remains the only effective treatment of ALF, but its availability is often limited by the chronic 
shortage of donor livers. Since a large number of patients will not have access to orthotopic liver transplantation, they will die while waiting for an organ. That emphasizes the need in developing new strategies for the management and treatment of ALF.

Despite several years of research, the complete comprehension of the pathogenesis of brain edema and hepatic encephalopathy in ALF remains incomplete. Mechanisms involving ammonia have also been proposed in the pathogenesis of cellular swelling and ultimately brain edema in acute liver failure. In an experimental model of acute liver failure, development of brain edema and declining neurological status were correlated with increasing arterial ammonia concentrations ${ }^{3}$.

The development of appropriate animal models of ALF is paramount for the understanding of the pathogenesis of ALF, the progression and management of the complications of ALF, and the mechanisms involved in liver regeneration. In addition, animal models are needed for the development and trial of new therapeutic approaches in ALF.

The most common approaches used to induce experimental ALF include surgical strategies, hepatotoxic drugs, and viral models. Among surgical approaches in rats, many strategies have been developed: total hepatectomy ${ }^{4}$, partial hepatectomy ${ }^{5}$, complete hepatic devascularization (a portacaval anastomosis followed by ligation of the hepatic artery ${ }^{6}$, and combined surgical/hepatotoxic models ${ }^{7}$.

The development of an ideal model of ALF has been remarkably difficult to achieve. The reproducibility of surgical models relies extensively on the availability of appropriate surgical expertise; however, one of their advantages is that they specifically affect the liver thus eliminating the problem of extrahepatic toxicity ${ }^{8}$.

A good model of ALF in rats is yet needed for further research concerning encephalopathy. The aim of this study was to develop a reliable surgical model of ALF and hyperammonemia in rats without the necessity of microsurgery skills, which avoids portosystemic shunt and bile duct ligation, applicable to hepatic encephalopathy research.

\section{Methods}

The study was designed in accordance with the Guide for the Care and Use of Laboratory Animals published by the US National Institutes of Health and the Guidelines of Animal Experimentation of the University of São Paulo School of Medicine, São Paulo, SP, Brazil, for the care and use of laboratory animals. The experimental protocol was pre-approved by Ethics Commission of the Hospital das Clínicas, University of São Paulo, Brazil.

Fourteen male Wistar rats weighing $250 \pm 5 \mathrm{~g}$ were housed in cages with a controlled 12-h light/dark cycle, receiving water ad libitum. Before the day of experiment animals fasted overnight but free access to water was allowed. Animals were anestethized with ketamin 5\% (30 mg/kg) and xylazine $2 \%(30 \mathrm{mg} / \mathrm{kg})$ intraperitonially. During the experiment animals were warmed by halogen light $(45 \mathrm{~W}, 127 \mathrm{~V})$ and corporeal temperature was controlled by digital thermometer (YSI Precision $4000 \mathrm{~A}$ thermometer, USA) and kept around $37^{\circ} \mathrm{C}$. Animals were maintained in spontaneous ventilation with an oxygen-enriched mixture $(40 \%)$ during all the procedure.

\section{Experimental design}

A median laparotomy was performed and the pedicles of right lateral and caudate lobes were clamped with an atraumatic microvascular bulldog clamp (Figure 1). In this technique, pedicle clamping is completely reversible, avoiding intestinal and caval stasis. After clamping, the abdominal wall was closed with uninterrupted 4-0 nylon suture in order to avoid dehydration. One hour later, the animal was reopened, clamps were released and $75 \%$ liver resection was performed for the removal of the median and left lateral lobes. Following this partial hepatectomy, the remaining liver consisted of the right lateral lobe, caudate lobe, and pericaval parenchyma (Figure 2). The abdominal wound was then closed. Blood samples and liver tissues were collected from ALF and CTRL groups, four hours after hepatectomy. At this time, all animals were space-disoriented and dizzy, probably due to hyperammonemia.

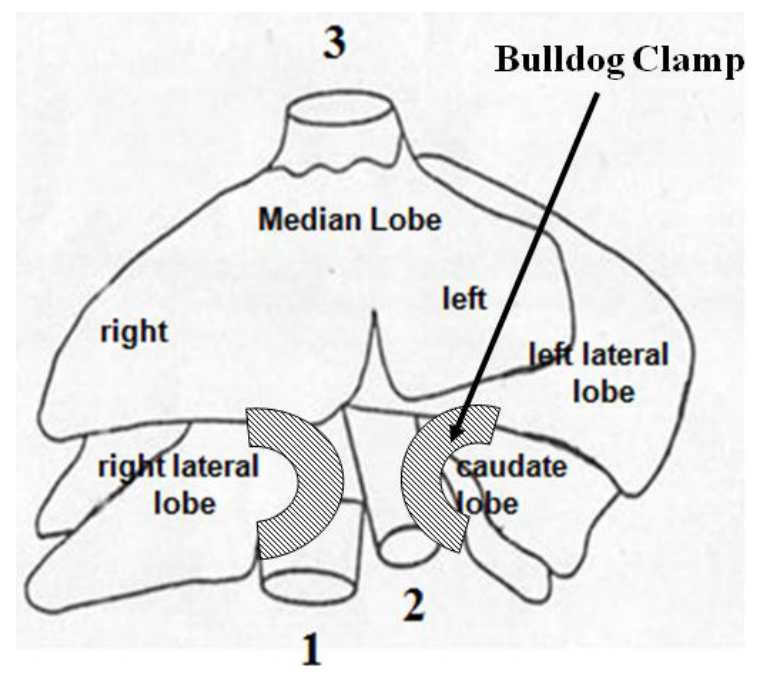

FIGURE 1 - Experimental design of rat partial hepatic ischemia. The pedicles of right lateral and caudate lobes were clamped to promote a sublethal ischemia of the liver. The blood flow remains stable into the median and left lateral lobes. 1. Infrahepatic vena cava. 2. Portal vein. 3. Suprahepatic vena cava 


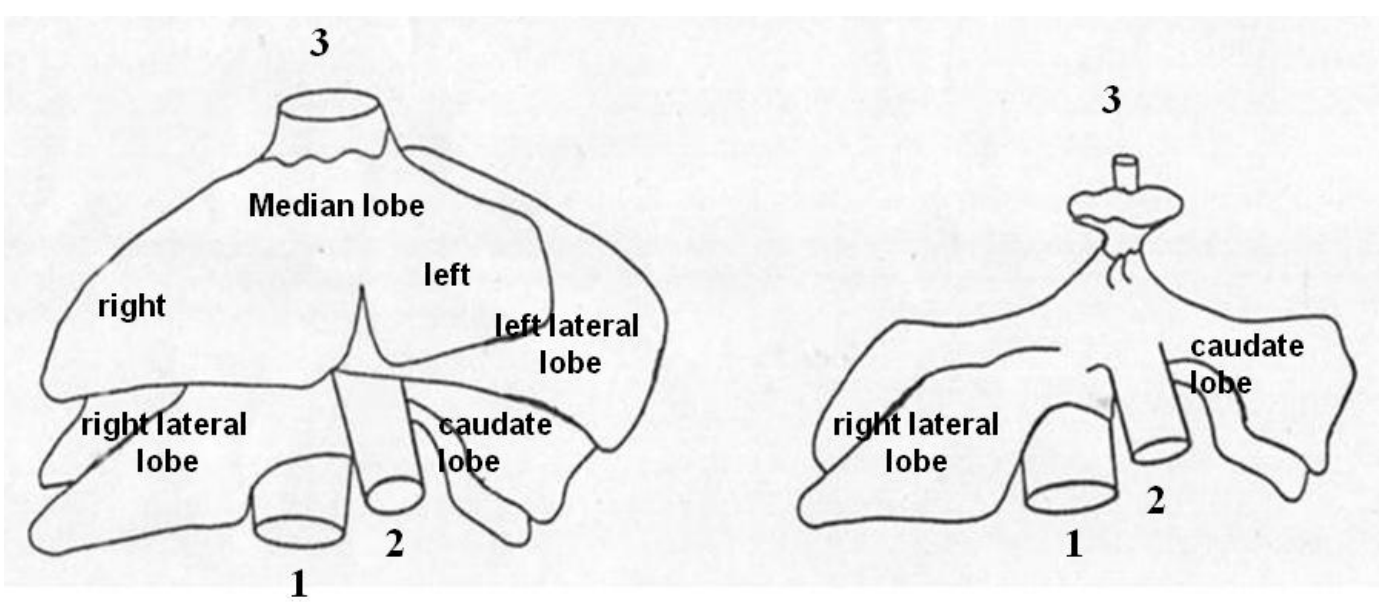

FIGURE 2 - Partial hepatectomy. After the resection of median and left lateral lobes, previously ischemic right lateral and caudate lobes remain. 1. Infrahepatic vena cava. 2. Portal vein. 3. Suprahepatic vena cava

\section{Blood sampling and analyses}

Albumin, hepatic enzymes [alanine aminotransferase (ALT), aspartate aminotransferase (AST), alkaline phosphatasis (AP) and gamma-glutamyltransferase], total and direct bilirubin, urea and creatinine levels were quantified using a clinical chemistry kit on Cobas Mira analyzer, according to the manufacturer's instructions.

Special attention was paid to specimen handling for analysis of ammonia levels. All samples were placed on ice immediately after collection and processed within 20 minutes. Serum ammonia levels were determined with a Cobas Integra 400 Analyzer. Sodium and potassium levels were determined with a Modular P Analyzer.

\section{Histological analysis}

Fragments of liver tissue previously fixed in $10 \%$ formalin solution were processed and stained with hematoxylineosin.

\section{Statistical analysis}

Comparisons between groups were statistically analyzed using GraphPad Prism 2.01 software. An unpaired t-test was performed. Mean values and SEM were displayed in graphics only as additional information. Differences were considered statistically significant when $p<0.05$.

\section{Results}

Alanine aminotransferase, aspartate aminotransferase, total and direct bilirubin, sodium, potassium, alkaline phosphatasis, gamma-glutamyltransferase and ammonia were assessed four hours after hepatectomy. Differences between ALF and CTRL groups were significant (Figures 3, 4 and 5).
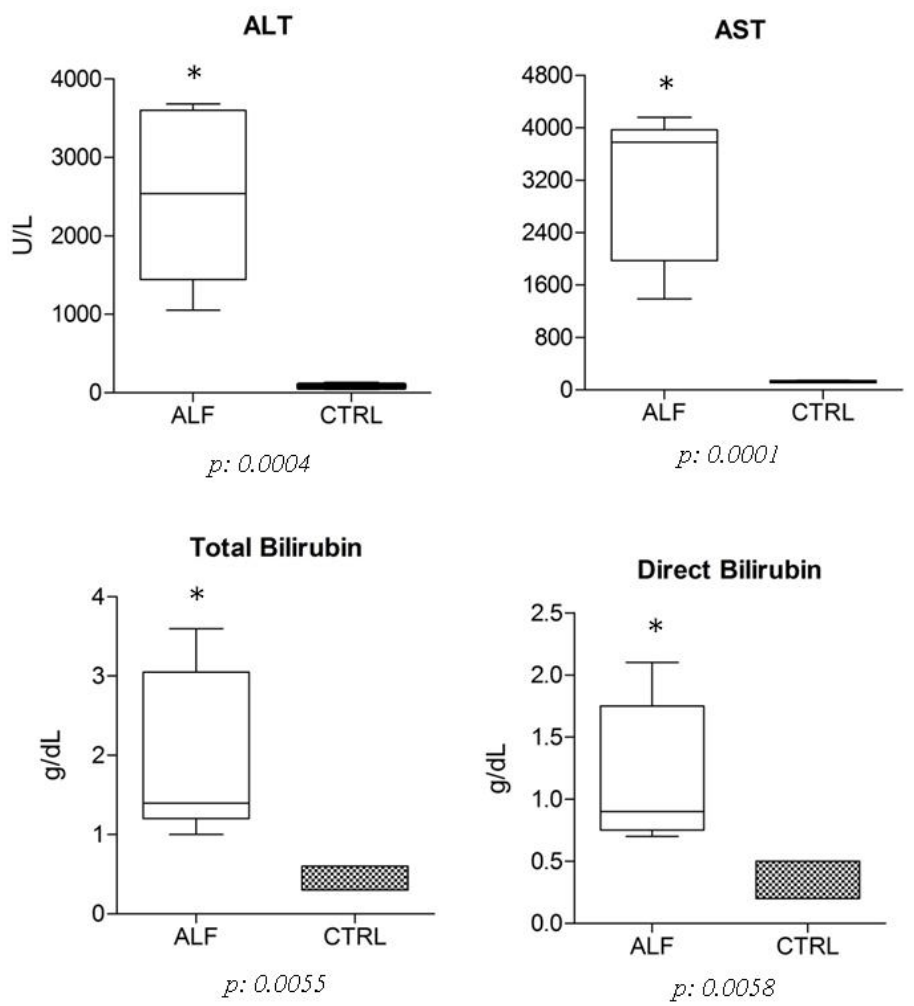

FIGURE 3 - Serum levels of alanine aminotransferase (ALT) (ALF group: $2526 \pm 498.5$, CTRL group: $81.67 \pm 7.032$ ), aspartate aminotransferase (AST) (ALF group: $3134 \pm 512.8$, CTRL group: $128.3 \pm 7.032$ ), total (ALF group: $1.980 \pm 0.476$, CTRL group: $0.400 \pm 0.063$ ) and direct (ALF group: $1.180 \pm 0.257$, CTRL group: $0.300 \pm 0.063$ ) bilirubin, four hours after hepatectomy 

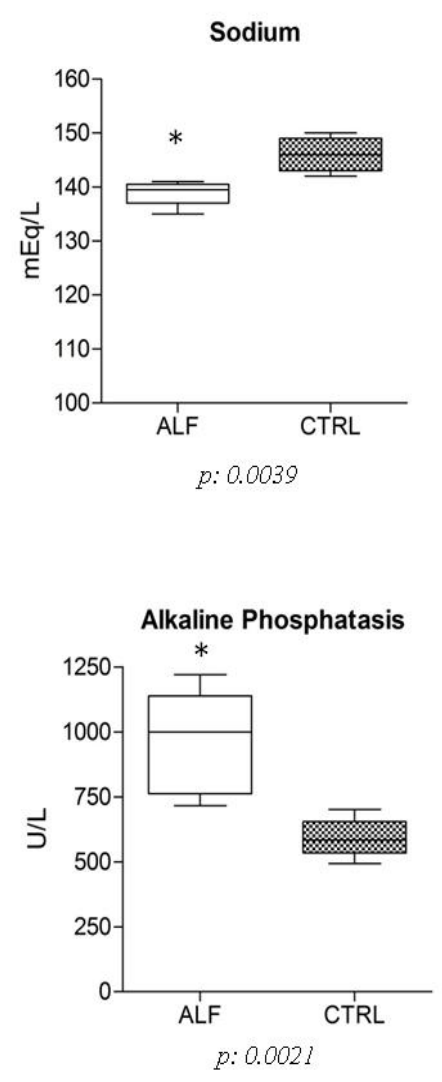

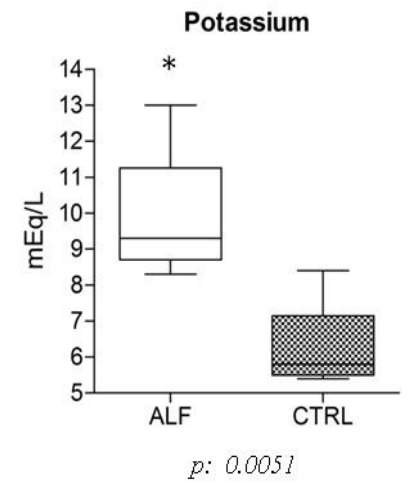

Gamma-Glutamyltransferase

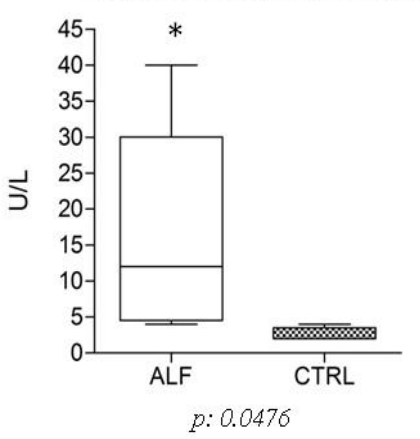

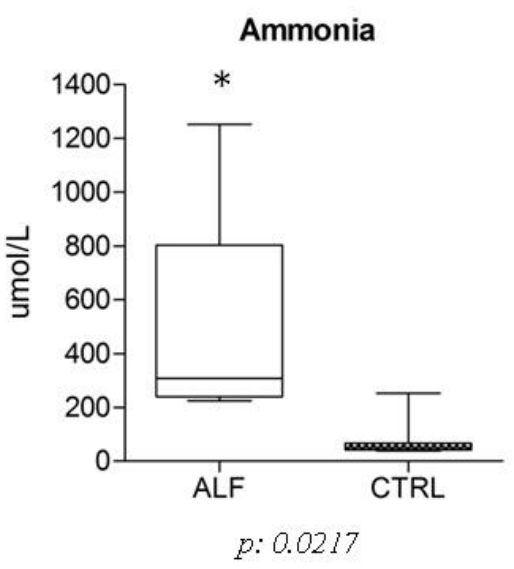

FIGURE 5 - Serum levels of ammonia (ALF group: $450.0 \pm 161.9$, CTRL group: $77.0 \pm 25.53$ ), four hours after hepatectomy
FIGURE 4 - Serum levels of sodium (ALF group: 138.8 \pm 1.315 , CTRL group: $146.0 \pm 1.183$ ), potassium (ALF group: 9.975 \pm 1.039 , CTRL group: $6.150 \pm 0.457$ ), alkaline phosphatasis (ALF group: 959.8 \pm 89.68 , CTRL group: $590.7 \pm 27.44$ ) and gammaglutamyltransferase (ALF group: 16.20 \pm 6.606 , CTRL group: $2500 \pm 0.342$ ) four hours after hepatectomy
There were no statistical differences between ALF and CTRL groups concerning albumin, creatinine and urea (Figure 6).
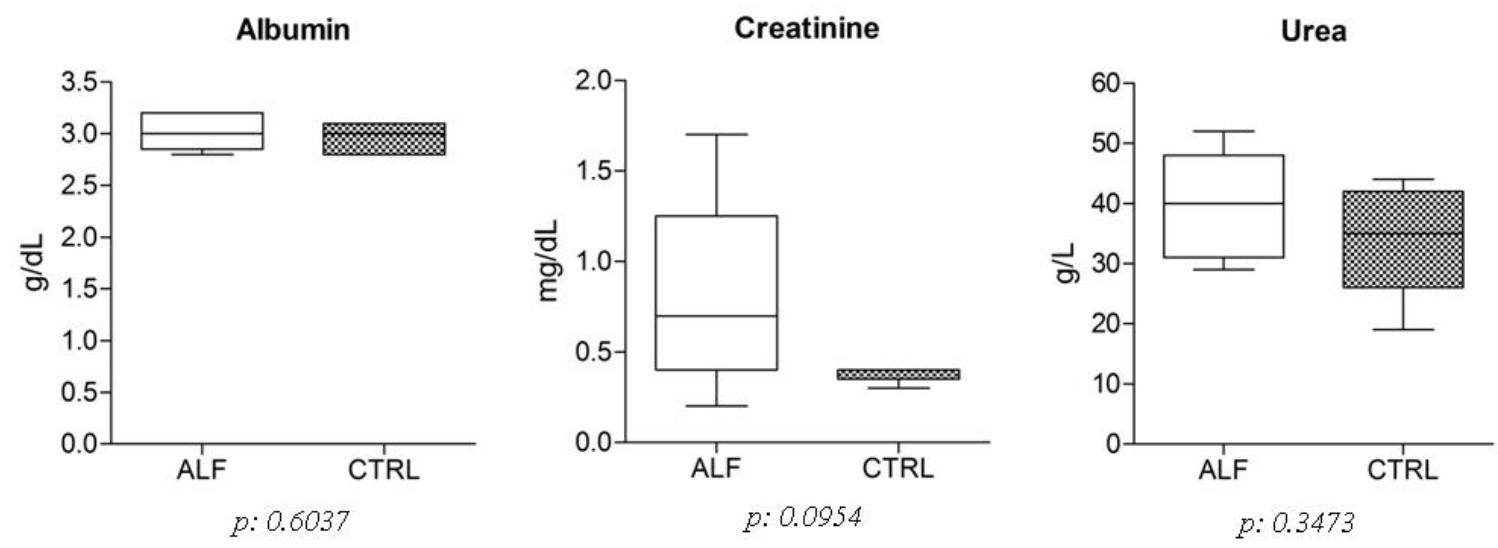

FIGURE 6 - Serum levels of albumin (ALF group: 3.020 \pm 0.080 , CTRL group: $2.967 \pm 0.0615$ ), creatinine (ALF group: $0.800 \pm 0.247$, CTRL group: $0.383 \pm 0.017$ ) and urea (ALF group: $39.6 \pm 4.057$, CTRL group: $34.33 \pm 3.480$ ), four hours after hepatectomy 
Histological liver assessment showed a menagerie of alterations in ALF group (Figure 7).
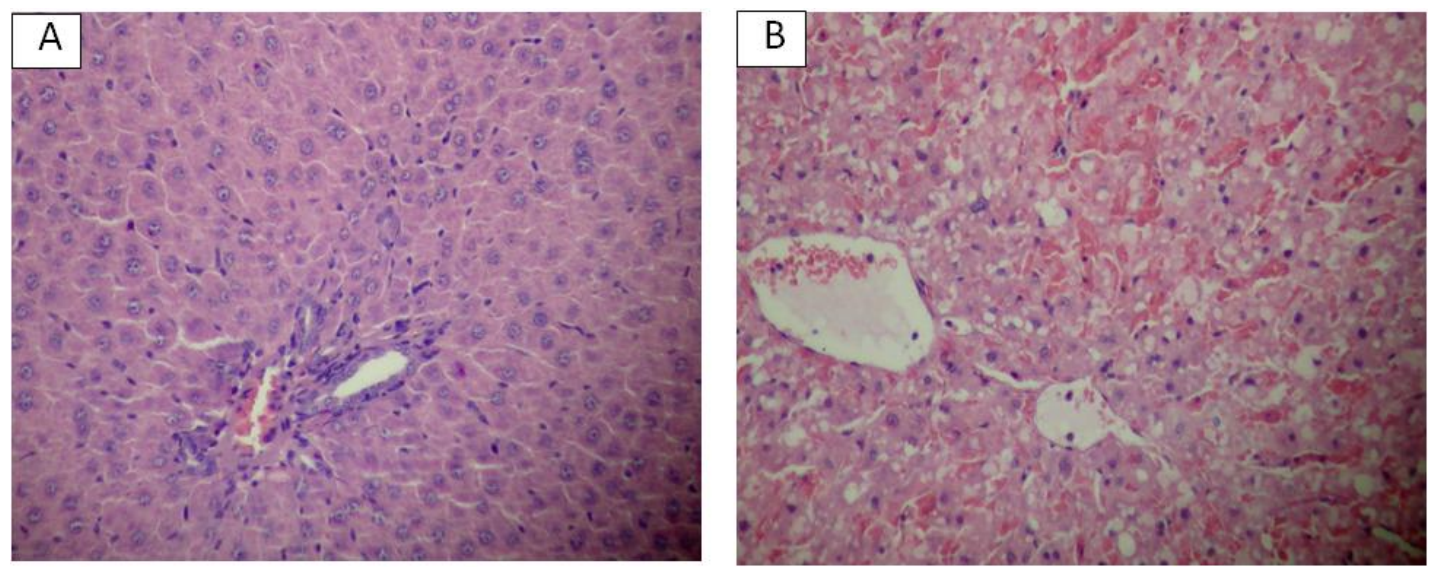

FIGURE 7 - Normal liver histology in CTRL group (A); Abnormal liver histology in ALF group (B) showing the presence of degenerative alterations: detrabeculation, microvesicular steatosis as well as diffuse and intense sinusoidal congestion (100X)

\section{Discussion}

Extensive resection of the liver results in ALF and mortality due to insufficient liver function of the remnant parenchyma. Under a certain threshold, however, partial hepatectomy is followed by intense liver regeneration and complete recovery ${ }^{5}$.

After a major hepatectomy, a small amount of remnant liver carries the duty of providing all energetic and metabolic necessities in the post-operative period. When the remaining liver is not sufficient, encephalopathy and coma take place and death is inevitable. This is a tragic situation that occurs sometimes in clinical situation. This also may occur in the set of living related liver transplantation, when the graft is small-for-size. Those two situations are catastrophic and must be avoided at most.

The comprehension of the mechanisms involved in the brain damage caused by hyperammonemia and ALF is vital. Thus, there is still a need for an experimental model that represents to the best the clinical situation?

In general, models of partial hepatectomy do not result in hepatic coma and do not mimetize the clinical picture seen in patients with ALF. These models, however, are well suited for the study of liver regeneration ${ }^{10}$.

In rats, it has been demonstrated that the high mortality observed following resection of $90 \%$ of liver mass ${ }^{5}$ can be greatly attenuated by the simple prevention of hypoglycemia ${ }^{11}$. Roger et al. ${ }^{11}$ proposed a model of $95 \%$ hepatectomy resulting in $80 \%$ mortality even with the control of hypoglycemia. Unfortunately, very little is known about the biochemical changes and the neurological symptoms occurring in this model ${ }^{11}$. Complete hepatic devascularization models (portocaval shunt and hepatic artery ligation, with or without bile duct ligation) are irreversible and result in death within a relatively short period of time. Animals show progressive encephalopathy and hepatic coma similar to those observed in patients with ALF. In addition, this model is accompanied by brain edema and raised intracranial pressure, which makes it useful for the study of these neurological complications of $\mathrm{ALF}^{12}$. In large animals, such models have been widely used to investigate the therapeutic potential of bioartificial and artificial liver support systems ${ }^{13}$. Nevertheless those models require advanced microsurgical skills and a high mortality rate is expected when performed in rats.

Studies in animal models of acute and chronic liver failure reveal significant increases in seric ammonemia and brain ammonia uptake. This effect is due to increased permeability of the blood-brain barrier in liver failure as well as to other factors such as alterations of cerebral blood flow ${ }^{14}$.

Our study mimetizes quite well human acute liver failure. Results of the present study reveal significant alterations in hepatic enzymes, sodium, potassium, total/direct bilirubin and hyperammonemia resulting from hepatic devascularization followed $75 \%$ liver resection. The precise mechanisms responsible for the induction of encephalopathy in liver failure are not completely understood. However, a number of studies suggest that hyperammonemia, which is a common feature of chronic and acute liver failure, is implicated. There is substantial evidence to suggest that hyperammonemia is one of the main factors contributing to the neurological alterations found in hepatic encephalopathy ${ }^{15}$. An understanding of the various mechanisms by which hyperammonemia exerts its effects, may provide a valuable approach to further elucidate the pathogenesis of hepatic encephalopathy and brain edema occurring as a result of acute liver failure.

In the present study, we developed a simple, not expensive, reproducible model of ALF and clinical encephalopathy in rats, using transient and restricted ischemia followed by a partial hepatectomy. This model does not need specific skills in microsurgery like others and it is similar to human clinical condition. The model is useful for the study of specific aspects of ALF and the development of new therapeutic approaches. An understanding of the various mechanisms by which hyperammonemia exerts its effects, may provide a valuable approach to further elucidate the pathogenesis of hepatic encephalopathy and brain edema occurring as a result of acute liver failure. 


\section{Conclusion}

The model is useful for the study of specific aspects of ALF and the development of new therapeutic approaches.

\section{References}

1. Lee WM, Squires RH Jr, Nyberg SL, Doo E, Hoofnagle JH. Acute liver failure: summary of a workshop. Hepatology. 2008;47:1401-15.

2. Gill RQ, Sterling RK. Acute liver failure. J Clin Gastroenterol. 2001;33:191-8.

3. Michalak A, Rose C, Butterworth J, Butterworth RF. Neuroactive amino acids and glutamate (NMDA) receptors in frontal cortex of rats with experimental acute liver failure. Hepatology. 1996;24:908-13.

4. Azoulay D, Astarcioglu I, Astarcioglu H, Lemoine A, Majno P, Bismuth H. A new technique of one-stage total hepatectomy in the rat. Surgery. 1997;121:219-22.

5. Panis Y, McMullan DM, Emond JC. Progressive necrosis after hepatectomy and the pathophysiology of liver failure after massive resection. Surgery. 1997;121:142-9.

6. Olafsson S, Gottstein J, Blei AT. Brain edema and intracranial hypertension in rats after total hepatectomy. Gastroenterology. 1995;108:1097-103.

7. Skawran S, Palmes D, Budny T, Bahde R, Stratmann U, Spiegel HU. Development and evaluation of an experimental model for investigating the pathogenesis and therapeutic strategies of acute liver failure. Transplant Proc. 2003;35:3142-6.
8. Bélanger M, Butterworth RF. Acute liver failure: a critical appraisal of available animal models. Metab Brain Dis. 2005;20:409-23.

9. Butterworth RF, Norenberg MD, Felipo V, Ferenci P, Albrecht J, Blei AT, Members of the ISHEN Commission on Experimental Models of HE. Experimental models of hepatic encephalopathy: ISHEN guidelines. Liver Int. 2009;29:783-8.

10. Kahn D, Hickman R, Terblanche J, von Sommoggy S. Partial hepatectomy and liver regeneration in pigs-the response to different resection sizes. J Surg Res. 1988;45:176-80.

11. Roger V, Balladur P, Honiger J, Delelo R, Baudrimont M, Robert A, Calmus Y, Capeau J, Nordlinger B. A good model of acute hepatic failure: $95 \%$ hepatectomy. Treatment by transplantation of hepatocytes. Chirurgie. 1996;121:470-3

12. Terblanche J, Hickman R. Animal models of fulminant hepatic failure. Dig Dis Sci. 1991;36:770-4.

13. Ytrebø LM, Nedredal GI, Langbakk B, Revhaug A. An experimental large animal model for the assessment of bioartificial liver support systems in fulminant hepatic failure. Scand J Gastroenterol. 2002;37:1077-88.

14. Dejong CH, Kampman MT, Deutz NE, Soeters PB. Cerebral cortex ammonia and glutamine metabolism during liver insufficiency-induced hyperammonemia in the rat. J Neurochem. 1992;59:1071-9.

15. Córdoba J, Mínguez B. Hepatic encephalopathy. Semin Liver Dis. 2008;28:70-80.

Conflict of interest: none Financial source: none

\section{Correspondence:}

Dra. Marta Bellodi-Privato

Faculdade de Medicina - USP

Av. Dr. Arnaldo, $455 / 3^{\circ}$ andar

01246-903 São Paulo - SP Brazil

martaprivato@hotmail.com

Received: December 14, 2009

Review: February 12, 2010

Accepted: March 18, 2010

\section{How to cite this article}

Teixeira ARF, Machado MCC, Kubrusly MS, Molan NT, Bellodi-Privato M, Leite KR, D'Albuquerque LAC. A new experimental model for acute hepatic failure in rats. Acta Cir Bras. [serial on the Internet] 2010 May-June;25(3). Available from URL: http://www.scielo.br/acb 